\title{
A PERCEPÇÃO AMBIENTAL ENTRE OS HABITANTES DA REGIÃO NOROESTE DO ESTADO DO RIO DE JANEIRO
}

\author{
Environmental Perception among Inhabitants of \\ Northwest Region of the State of Rio de Janeiro \\ La Percepción del Medio Ambiente entre los \\ Habitantes de la Región Noroeste de Rio de Janeiro
}

Livia Melo Villar ${ }^{1}$

Juliana Lauredo Valle de Almeida ${ }^{4}$
Adilson José de Almeida²

Lilian Fiori Boechat de Souza ${ }^{5}$
Michele Christiane Andrade de Lima ${ }^{3}$

Vanessa Salete de Paula ${ }^{6}$

\section{Resumo}

Foi desenvolvido um estudo para avaliar a percepção ambiental de indivíduos residentes do Município de Itaperuna, localizado na região Noroeste do Rio de Janeiro, Brasil. Foram selecionados 243 indivíduos, entre os meses de julho a outubro de 2005, que responderam sobre questões que abordavam a relação indivíduo/ambiente; ações individuais em favor da área ambiental; preocupação com o impacto ambiental e consumo; hábitos pessoais e ambiente. Com base na análise das respostas dos indivíduos, foi observada maior percepção ambiental em indivíduos mais velhos em relação a crianças e jovens. Este resultado demonstra que os programas de educação ambiental nesta região devem ser voltados para crianças e adolescentes, para que os mesmos se tornem adultos conscientes, uma vez que os indivíduos respondentes apresentaram grande interesse pelos temas ambientais e disposição para participar de campanhas e ações de recuperação ambiental.

Palavras-chave: Percepção. Educação Ambiental. Saúde.

\section{Abstract}

A research was developed to evaluate the environmental perception of individuals living in Itaperuna City, located in the northwest region of the State of Rio de Janeiro, Brazil. Between July and October 2005 a total of 243 individuals were interviewed concerning issues such as individual/environmental relation; individual actions in favor to environmental education; individual actions in favor to environmental area; concern about environmental impact and consumption; personal customs and environment. Based on the analysis of the answers of the individuals, a greater environmental perception was observed in elder individuals in relation to children and young adults. This result demonstrate that environmental education programs in this region should be focused on children and adolescents, in order to make these individuals more conscientious adults, since interviewed individuals presented great interest concerning environment issues and willingness to participate in campaigns and actions of environmental recovering.

Keywords:

Perception. Environmental Education. Health.

\section{Resumen}

Se desarrolló una investigación para evaluar la percepción ambiental de las personas que viven en la ciudad Itaperuna, situada en la región noroeste del Rio de Janeiro, Brasil. Se entrevistaron 243 personas entre julio y octubre de 2005 sobre cuestiones acerca de la relación de la persona sobre el medio ambiente; las acciones a favor de la educación ambiental; las acciones a favor del medio ambiente de la zona; beligerantes acerca del impacto ambiental y de consumo, hábitos personales y el medio ambiente. Cuando las respuestas de esta población se compararon, se observó una gran percepción ambiental en el anciano de los individuos en relación con los niños y adultos jóvenes. Este resultado demostra que programas de educación ambiental en esta región se deben enfocar para los niños y los adolescentes, para que estos se conviertan en adultos más consciente, ya que las personas entrevistadas presentaron gran interés sobre temas de medio ambiente y disposición a participar en campañas y acciones de recuperación ambiental.

Palabras clave:

Percepción. Educación Ambiental. Salud. 


\section{INTRODUÇ̃̃O}

A percepção ambiental pode ser definida como sendo uma tomada de consciência das problemáticas ligadas ao ambiente, ou seja, 0 ato de perceber o ambiente em que se está inserido, aprendendo a proteger e a cuidar do mesmo ${ }^{1}$. Também pode ser definido pelas formas como os indivíduos vêem, compreendem e se comunicam com o ambiente, considerandose as influências ideológicas de cada sociedade ${ }^{2}$. As respostas ou manifestações daí decorrentes são resultados das percepções, individuais e coletivas, dos processos cognitivos, julgamentos e expectativas de cada pessoa.

Uma das dificuldades para a proteção dos ambientes naturais está na existência de diferenças nas percepções dos valores e da importância dos mesmos entre os indivíduos de culturas diferentes ou de grupos sócio-econômicos que desempenham funções distintas, no plano social, nesses ambientes. A educação e percepção ambiental despontam como armas na defesa do meio natural e ajudam a reaproximar 0 homem da natureza, garantindo um futuro com mais qualidade de vida para todos, já que despertam maior responsabilidade e respeito dos indivíduos em relação ao ambiente em que vivem ${ }^{3}$. Mais ainda, a percepção sobre as doenças existentes e suas formas de transmissão, prevenção e controle torna-se importante na medida em que os indivíduos passam a adotar medidas capazes de protegê-los dessas doenças.

Ao profissional de saúde cabe investigar inicialmente como a comunidade se relaciona com o ambiente e, conseqüentemente, identificar os obstáculos existentes para, a partir de então, implementar ações de educação sanitária e ambiental ${ }^{4}$.

Aos poucos, percebe-se que uma grande quantidade de pessoas, ligadas a organizações não-governamentais, universidades, empresas e órgãos do governo, tem se juntado, dispostas a trabalhar pela conservação do meio ambiente e pela inclusão social. Mesmo parecendo estar solitárias nessas batalhas, essas pessoas costumam mobilizar outras, na busca de soluções criativas e eficientes para preservar 0 ambiente em que vivem. No entanto, a grande maioria da população ainda não atinou com a importância de certos temas, não tomando tais questões como bandeiras de luta.

Assim, 0 estudo da percepção ambiental é de fundamental importância para uma melhor compreensão da inter-relação homem-ambiente, levando em conta suas expectativas, satisfações e insatisfações, julgamentos e condutas. 0 presente trabalho teve o objetivo de avaliar a percepção ambiental dos indivíduos residentes do Município de Itaperuna, localizado na região Noroeste do Estado do Rio de Janeiro, Brasil, sobre o impacto de suas atividades no ambiente, assim como a relação cognitiva e emocional com o mesmo, de forma a traçar um diagnóstico sócio-ambiental local para fornecer subsídios às ações e aos projetos de gestão ambiental e educação sanitária nessa região.

\section{METODOLOGIA}

0 Município de Itaperuna está localizado na região Noroeste do Estado do Rio de Janeiro, com extensão territorial de $1.109,5 \mathrm{~km}^{2}$, equivalentes a $20,6 \%$ da região Noroeste
Fluminense ${ }^{5}$. Dista da Capital do Estado, a Cidade do Rio de Janeiro, cerca de $320 \mathrm{~km}$. As peculiaridades do relevo e da hidrografia do Município de Itaperuna são a Serra de Monte Alegre, o relevo acidentado da Serra da Mantiqueira e o Rio Muriaé com seus afluentes. 0 Rio Muriaé nasce na Serra da Mantiqueira, possui curso torrencial e apresenta várias quedas de água, merecendo destaque as Cachoeiras da Fumaça, São Miguel e Limoeiro. Os recursos hídricos propiciados pelo rio são da maior importância para o abastecimento de água do Município de Itaperuna e desenvolvimento da cultura de arroz em todo o Município. 0 clima é tropical úmido, variando a temperatura de $15^{\circ} \mathrm{C}$ a $42^{\circ} \mathrm{C}$ durante o verão. Apresenta duas estações muito distintas em relação às chuvas: é razoavelmente chuvosa no período que vai de novembro a março e tem um período muito seco que vai do final de outono e acompanha o inverno.

A população do Município de Itaperuna foi estimada, em 2003, em 89.406 pessoas $^{5}$ e representa 29\% da população do Noroeste Fluminense.

Quanto à distribuição por zona de moradia, verificou-se que, no ano 2000, 89,23\% residiam na zona urbana e 10,77 \%, na zona rural. Em relação à distribuição da população por distrito, foi relatado que a maioria $(70,82 \%)$ residia no Distrito Central de Itaperuna.

Quanto à estrutura etária, $24,8 \%$ da população estão entre $0 \mathrm{e}$ 15 anos; $57,8 \%$, entre 20 e 64 anos; e 7,6\% da população têm 65 anos ou mais de vida. A faixa etária predominante encontra-se entre os 10 e 39 anos, e idosos representam $11 \%$ da população do município, contra $16 \%$ de crianças entre 0 e 9 anos.

Com relação ao abastecimento de água, Itaperuna possui $87,2 \%$ dos domicílios com acesso à rede de distribuição, 10,6\% com acesso à água através de poço ou nascente, e 2,2\% têm outra forma de acesso à água. 0 total distribuído alcança 27.911 metros cúbicos por dia, dos quais a totalidade passa por tratamento convencional. A rede coletora de esgoto sanitário chega a 82,0\% dos domićílios do Município; outros 3,2\% têm fossa séptica, 2,9\% utilizam fossa rudimentar, 7,8\% estão ligados a uma vala, e 3,0\% são lançados diretamente em um corpo receptor (rio, lagoa ou mar). 0 esgoto coletado não passa por tratamento e é lançado no rio e em outro corpo receptor não identificado. Itaperuna possui $86,7 \%$ dos domicílios com coleta regular de lixo, outro $1,1 \%$ tem seu lixo jogado em terreno baldio ou logradouro, e $11,6 \%$ o queimam. 0 total de resíduos sólidos coletados somava 60 toneladas por dia, tendo como destinos seis vazadouros a céu aberto (lixões) e um aterro controlado ${ }^{5}$.

0 Noroeste Fluminense, pelo forte desmatamento, uso e ocupação inadequados do solo, apresenta diversos problemas ambientais, que se manifestam com diferentes graus críticos, como por exemplo:

- Insuficiência ou ausência de infra-estrutura de saneamento básico (água, esgoto e disposição inadequada de lixo) acarretando a poluição das águas dos rios e lençóis de água, além da proliferação de vetores;

- Desmatamento provocando a erosão acelerada do solo e o comprometimento dos mananciais, além de ocasionar grandes e sistemáticas inundações e enchentes; 
- Práticas agrícolas inadequadas, comprometendo a qualidade do solo e provocando a erosão acelerada, além da contaminação do solo e das águas pelo uso excessivo de agrotóxicos;

- Métodos inapropriados de exploração mineral, ocasionando desperdícios, disposição inadequada e sem aproveitamento dos resíduos.

Atualmente, o desenvolvimento sustentável é uma das principais metas de diversas instituições públicas ou privadas, o que torna imprescindível o conhecimento da percepção ambiental da população que a cerca nas tomadas de decisão. A fim de fornecer subsídios para implantação de um projeto de educação ambiental no Município de Itaperuna, foi elaborado um estudo prospectivo, com delineamento transversal, tendo como instrumento um questionário (Anexo 1) contendo 4 domínios (A - Relação indivíduo/ambiente; B- Ações individuais em favor do ambiente; C- Preocupação com o impacto ambiental e consumo; D - Hábitos pessoais e ambiente), com 18 questões dos tipos abertas, fechadas e mistas, enfocando principalmente os problemas ambientais da cidade e o tipo de trabalho realizado pela comunidade para a análise e enfrentamento das questões ambientais.

A presença de consciência ambiental foi avaliada nas diferentes questões, com exceção dos itens A1-A2, B3 e C1, através de respostas afirmativas. Consideraram-se como ausência de consciência ambiental as respostas negativas ou a incapacidade de informar em cada um dos itens incluídos no questionário. Após elaboração do questionário, 243 indivíduos responderam ao mesmo entre os meses de julho a outubro de 2005 durante um evento de negócios da região, a MercoNoroeste (Feira Industrial e Comercial do Noroeste Fluminense), em Itaperuna, por uma equipe composta de 20 discentes e 4 docentes do Curso de Ciências Biológicas da Faculdade Redentor (Itaperuna, RJ). Os dados coletados de forma consecutiva durante a aplicação do questionário foram armazenados em uma pasta de trabalho criada no Microsoft Office Excel 2007 (Microsoft Corporation, EUA) utilizando-se a ferramenta de dados. Na construção desta, foram realizadas as seguintes etapas: determinação de que cada uma das perguntas corresponderia a uma variável, codificação das variáveis categóricas e questões fechadas com respostas mais abrangentes e mutuamente exclusivas.

Os dados foram apresentados em freqüências e mediana com faixa de variação e desvio interquartil (DIQ) para variável quantitativa que não apresenta distribuição normal (análise univariada). Na análise bivariada, foi utilizado o teste QuiQuadrado para tendência para comparar proporções. Um valor de $P<0,05$ (teste bicaudal) foi considerado estatisticamente significante. Todas as análises foram realizadas utilizando-se o pacote estatístico GraphPad Instat versão 3.05 (GraphPad Software, San Diego, Califórnia, EUA).

Em respeito aos princípios contidos na Resolução n 196/ 96 do Conselho Nacional de Saúde (Brasil), no que diz respeito à participação dos sujeitos na pesquisa: foram esclarecidos acerca do objetivo do estudo, de que poderiam recusar a participar sem que isso implicasse em qualquer prejuízo; que tal participação não envolveria custo financeiro, e que não era previsto nenhum dano. Também foram informados de que seria assegurado o anonimato na divulgação dos resultados desta pesquisa, e que esse trabalho acadêmico seria apresentado em eventos e periódicos científicos.

\section{RESULTADOS}

A análise preliminar dos dados obtidos a partir da aplicação do questionário aos 243 indivíduos residentes do Município de Itaperuna revelou que 124 (51\%) indivíduos eram do sexo feminino e 119 (49\%) indivíduos eram do sexo masculino, indicando participação muito similar de ambos os sexos no estudo. Esta amostra foi composta de indivíduos com idade mediana de 35,0 anos (9 - 88 anos; DIQ, 28 anos).

Em relação ao domínio $\mathrm{A}$ (relação indivíduo/ambiente), as duas respostas mais referidas para a questão " 0 que significa ambiente?" foram: lugar em que se vive $(71 / 29,2 \%)$ e natureza (45/18,5\%). Outras respostas como preservação, saúde, limpeza, harmonia, entre outras, foram agrupadas em categoria única. Foi observada associação estatística significante $(P=0,0250)$ entre esta questão e a faixa etária, com tendência de aumento de outras respostas na medida em que a idade avança. Com relação à questão "Quais doenças podem ser transmitidas pela água?", Verminose (50/20,6\%), Dengue (46/ $18,9 \%)$, Leptospirose $(28 / 11,5 \%)$ e Hepatite $(20 / 8,2 \%)$ foram as mais referidas, e 57 (23,5\%) não souberam responder. As doenças transmitidas pela água, incluindo doenças diversas como cólera, micose, diarréia, febre amarela e malária, foram referidas com maior freqüência por indivíduos com idade igual ou acima de 16 anos. Uma associação estatística significante foi observada entre esta variável e faixa etária $(P=0,0006)$.

Com relação ao domínio $B$ (ações individuais em favor do ambiente), 126 (51,9\%) indivíduos relataram que escovam os dentes com a torneira aberta, porém 125 (51,4\%) fecham a torneira enquanto se ensaboam durante o banho. Este último (item B2) foi associado significantemente à faixa etária $(P=0,0017)$, indicando uma tendência de aumento desta prática na medida em que a idade aumenta. Quanto à forma de lavagem dos carros (item B3), 60 (24,6\%) indivíduos relataram que tal procedimento era realizado em postos ou lava-jatos. Entretanto, entre os que lavavam seus carros em casa, 50 indivíduos o faziam com auxílio de mangueira e 14 usavam baldes para evitar o desperdício de água. Em relação ao desperdício de energia (item B4), 183 (75,3\%) indivíduos relataram que desligavam aparelhos eletrodomésticos ou a luz quando não estavam em um dos cômodos da casa. Em relação ao lixo (itens B5, B6 e B7), 99 (40,7\%) indivíduos separavam o lixo orgânico (comida) do inorgânico (vidro, jornais, plástico) na hora de jogá-lo fora, 70 (28,8\%) separavam papel, vidro, plástico e metais na hora de jogar fora o lixo (161/243), e apenas 58 (23,9\%) faziam alguma reciclagem do seu lixo. As práticas de separação de papel, vidro, plástico e metais na hora descartar o lixo $(P=0,0016)$ e reciclagem do lixo $(P=0,0173)$ mostraram-se significantemente relacionadas à faixa etária.

Em relação à preocupação com o impacto ambiental e consumo (domínio C), apenas 61 indivíduos possuíam veículo automotor, e destes, 37 referiram o uso de gasolina e cinco 
indivíduos, o uso de GNV. Em relação à questão "Você procura comprar material biodegradável, como alguns detergentes?" (item C2), verificamos que 155 (63,8\%) indivíduos apresentaram resposta afirmativa. Quanto à questão "Você procura comprar produtos somente em aerossóis que tenham em seu rótulo a inscrição "Não possui CFC"?", apenas 61 (25,1\%) indivíduos relataram a procura por produtos desta natureza. 0 hábito de escutar aparelhos eletrônicos com volume elevado (item C4) foi reportado por $162(66,7 \%)$ indivíduos. As variáveis: uso de detergentes biodegradáveis $(P=0,0002)$ e uso de

Tabela 1

Freqüência do status de percepção ambiental avaliado através de diferentes itens abordados no questionário em relação à faixa etária da amostra estudada $(n=243)$ no Município de Itaperuna, 2005.

\begin{tabular}{|c|c|c|c|c|c|c|}
\hline \multirow{2}{*}{ Questão } & \multicolumn{5}{|c|}{$\begin{array}{l}\text { Faixa Etária } \\
\text { (anos) }\end{array}$} & \multirow{2}{*}{$\begin{array}{c}\text { Análise } \\
\text { Bivariada } \\
\quad P\end{array}$} \\
\hline & $n(\%)$ & $0-15$ & $16-30$ & $31-45$ & $>45$ & \\
\hline 0 que significa ambiente? & & & & & & 0,0250 \\
\hline Natureza & $45(18,5)$ & $5(2,0)$ & $24(9,9)$ & $8(3,3)$ & $8(3,3)$ & - \\
\hline Lugar em que vive & $71(29,2)$ & $8(3,3)$ & $25(10,3)$ & $15(6,2)$ & $23(9,4)$ & - \\
\hline Outras respostas & $84(34,6)$ & $6(2,5)$ & $19(7,8)$ & $22(9,0)$ & $37(15,3)$ & - \\
\hline Não sabe & $43(17,7)$ & $6(2,5)$ & $15(6,2)$ & $11(4,5)$ & $11(4,5)$ & - \\
\hline $\begin{array}{l}\text { Quais doenças podem } \\
\text { ser transmitidas pela água? }\end{array}$ & & & & & & 0,0006 \\
\hline Verminose & $50(20,6)$ & $4(1,6)$ & $11(4,5)$ & $16(6,7)$ & $19(7,8)$ & - \\
\hline Dengue & $46(18,9)$ & $5(2,1)$ & $17(7,0)$ & $9(3,6)$ & $15(6,2)$ & - \\
\hline Leptospirose & $28(11,5)$ & $3(1,2)$ & $15(6,2)$ & $6(2,5)$ & $4(1,6)$ & - \\
\hline Hepatite & $20(8,2)$ & $0(0,0)$ & $6(2,4)$ & $7(2,9)$ & $7(2,9)$ & - \\
\hline Outras respostas & $42(17,3)$ & $0(0,0)$ & $21(8,7)$ & $11(4,4)$ & $10(4,2)$ & - \\
\hline Não sabe & $57(23,5)$ & $13(5,4)$ & $13(5,4)$ & $7(2,9)$ & $24(9,8)$ & - \\
\hline $\begin{array}{l}\text { Você fecha a torneira enquanto } \\
\text { se ensaboa durante o banho? }\end{array}$ & & & & & & 0,0017 \\
\hline Sim & $125(51,4)$ & $12(4,9)$ & $30(12,3)$ & $32(13,2)$ & $51(21,0)$ & - \\
\hline Não & $118(48,6)$ & $13(5,4)$ & $53(21,9)$ & $24(9,8)$ & $28(11,5)$ & - \\
\hline $\begin{array}{l}\text { Você separa papel, vidro, plástico e } \\
\text { metais na hora de jogar fora o lixo? }\end{array}$ & & & & & & 0,0016 \\
\hline $\operatorname{Sim}$ & $70(28,8)$ & $7(2,9)$ & $12(4,9)$ & $18(7,4)$ & $33(13,6)$ & - \\
\hline Não & $173(71,2)$ & $18(7,4)$ & $71(29,3)$ & $38(15,6)$ & $46(18,9)$ & - \\
\hline $\begin{array}{l}\text { Você faz alguma reciclagem } \\
\text { do seu lixo? }\end{array}$ & & & & & & 0,0173 \\
\hline $\operatorname{Sim}$ & $58(23,9)$ & $8(3,3)$ & $15(6,2)$ & $16(6,6)$ & $19(7,8)$ & - \\
\hline Não & $185(76,1)$ & $17(7,0)$ & $68(28,0)$ & $40(16,4)$ & $60(24,7)$ & - \\
\hline $\begin{array}{l}\text { Você procura comprar material } \\
\text { biodegradável, como alguns detergentes? }\end{array}$ & & & & & & 0,0002 \\
\hline $\operatorname{Sim}$ & $155(63,8)$ & $6(2,5)$ & $50(20,6)$ & $43(17,7)$ & $56(23,0)$ & - \\
\hline Não & $88(36,2)$ & $19(7,8)$ & $33(13,6)$ & $13(5,3)$ & $30(9,5)$ & - \\
\hline $\begin{array}{l}\text { Você escuta aparelhos eletrônicos } \\
\text { com volume elevado? }\end{array}$ & & & & & & $<0,0001$ \\
\hline $\operatorname{Sim}$ & $162(66,7)$ & $12(5,8)$ & $54(15,3)$ & $21(16,0)$ & $9(29,6)$ & - \\
\hline Não & $81(33,3)$ & $12(4,5)$ & $26(18,9)$ & $33(7,0)$ & $65(2,9)$ & - \\
\hline Joga lixo na rua? & & & & & & $<0,0001$ \\
\hline $\operatorname{Sim}$ & $202(83,1)$ & $14(5,7)$ & $63(25,9)$ & $50(20,6)$ & $75(30,9)$ & - \\
\hline Não & $41(16,9)$ & $11(4,6)$ & $20(8,3)$ & $6(2,4)$ & $4(1,6)$ & - \\
\hline $\begin{array}{l}\text { Você escova os dentes após cada } \\
\text { refeição, inclusive após comer } \\
\text { doces, todos os dias? }\end{array}$ & & & & & & 0,0447 \\
\hline $\operatorname{Sim}$ & $202(83,1)$ & $18(7,4)$ & $67(27,6)$ & $47(19,3)$ & $70(28,8)$ & - \\
\hline Não & $41(16,9)$ & $7(2,9)$ & $16(6,6)$ & $9(3,7)$ & $9(3,7)$ & - \\
\hline Você cospe no chão? & & & & & & $<0,0001$ \\
\hline $\operatorname{Sim}$ & $171(70,4)$ & $15(6,2)$ & $47(19,3)$ & $43(17,7)$ & $66(27,2)$ & - \\
\hline Não & $72(29,6)$ & $10(4,1)$ & $36(14,9)$ & $13(5,3)$ & $13(5,3)$ & - \\
\hline
\end{tabular}


aparelhos eletrônicos com volume alto $(P<0,0001)$ foram estatisticamente relacionadas à faixa etária.

Em relação aos hábitos pessoais e ambiente (domínio D), foi verificado que $202(83,1 \%)$ respondentes jogam lixo nas ruas ou rios (item D1), $202(83,1 \%)$ escovam os dentes após cada refeição (item D2), 204 (84,0\%) lavam as mãos com sabão ao se levantarem de manhã, antes de comer e após ter ido ao banheiro (item D3), 171 (70,4\%) cospem no chão (item D4), e $222(91,4 \%)$ realizam limpeza constante do local onde moram (item D5). As variáveis relacionadas aos itens D1, D2 e D4 foram estatisticamente associadas à faixa etária: os hábitos de jogar lixo no ambiente e cuspir no chão tornam-se mais freqüentes à medida que a idade avança, assim como escovar os dentes após as refeições. Os resultados da análise bivariada foram apresentados na Tabela 1.

\section{DISCUSSÃO}

A avaliação da percepção ambiental desperta a atenção da população para os problemas ambientais tornando-a mais consciente e mais exigente quanto às atitudes mais ecológicas de dirigentes, sejam prefeitos, governadores, presidentes, diretores, etc. ${ }^{6} \mathrm{~A}$ aplicação do questionário pelos alunos e professores do Curso de Ciências Biológicas da Faculdade Redentor possibilitou uma análise a respeito da percepção ambiental desta população a fim de desenvolver um programa de educação ambiental e sanitária dirigido aos problemas que afligem o meio ambiente urbano no Município de Itaperuna. Os resultados mostraram que os indivíduos da amostra estudada apresentam um bom nível de consciência ambiental em relação aos itens abordados no questionário. Por outro lado, não se pode excluir a possibilidade de que parte das respostas fornecidas pelos indivíduos não deve refletir as práticas executadas pelos mesmos, pois uma parcela dos indivíduos prefere negar a sua condição (falsa-resposta), por considerar estas atitudes incorretas.

Ao avaliarmos a relação indivíduo/ambiente (domínio A), observamos que a noção sobre ambiente era heterogênea entre os indivíduos estudados, com o conceito de ambiente tendendo a variar com o aumento da idade. A maioria dos indivíduos definiu ambiente como o local onde se vive e natureza mostrando noção sobre o conceito de ambiente, apesar da falta de um programa de Educação Ambiental formal naquela região. Ainda com relação a este domínio, ao avaliarmos a noção sobre doenças transmitidas pela água, observamos que os indivíduos da população de Itaperuna têm o conhecimento sobre várias doenças que podem ser transmitidas por este veículo. Entretanto, a dengue, por exemplo, foi erroneamente e em alta freqüência referida como uma daquelas doenças, possivelmente como resultado do grande número de propagandas sobre esta doença, embora seja preciso esclarecer que não é a água a fonte de transmissão, mas sim o inseto vetor. Isto mostra a necessidade de se fazerem programas de saúde que alertem a população para a ocorrência de outras doenças veiculadas através da água, assim como a forma com que a água pode ocasionar estas doenças. Observamos também que muitas pessoas não sabiam que a ingestão de água contaminada pode ocasionar doenças como hepatites, gastroenterites, ou que o contato físico com água contendo miracídios pode levar à transmissão da esquistossomose. Isto também foi observado por Comi et al. ${ }^{7}$ em estudo realizado em Uruguaiana (RS), onde a maioria dos indivíduos do estudo desconhecia que vetores e água podem ocasionar doenças graves, por vezes com êxito fatal. Estes dados mostram que as campanhas devem informar com mais clareza as doenças de veiculação hídrica que podem ser associadas à falta de saneamento adequado e que profissionais de saúde são fundamentais para o esclarecimento dessas questões junto às populações.

Outro ponto avaliado foi a ação individual sobre o ambiente (domínio B) onde os pontos estatisticamente significantes foram relacionados às questões "Você fecha a torneira enquanto se ensaboa durante o banho? Você separa papel, vidro, plástico e metais na hora de jogar fora o lixo? Você faz alguma reciclagem do seu lixo?". Isto demonstra que esta população apresenta noção destes atos, mas que muitas vezes estes são realizados inconscientemente com intuito de limpeza e não de reciclagem. A coleta seletiva que permite a separação do lixo reciclável (vidro, plásticos, papel e metal) do restante faz com que este resíduo, ao ser desprezado, passe a ser considerado matériaprima, podendo ser transformado e reutilizado pela própria população. No momento da realização deste estudo, não havia um sistema de recolhimento de materiais recicláveis, tais como papéis, plásticos, vidros e metais, mas atualmente um projeto piloto está sendo implantado em algumas ruas do bairro Cidade Nova e Lions para viabilizar a coleta seletiva de resíduos sólidos no Município de Itaperuna.

Observamos que os indivíduos tendem a apresentar maior consciência em relação à questão do lixo à medida que se tornam mais velhos, demonstrando que programas de educação ambiental devem ser construídos para fornecer estas noções às faixas etárias mais jovens como crianças e adolescentes, os quais poderão se tornar multiplicadores desta informação. A educação ambiental, para ser efetiva, não deve ser apresentada de forma verticalizada, do tipo educador-educando, mas sim reflexiva, construída ${ }^{8}$.

Em relação à preocupação com o impacto ambiental e consumo (domínio C), observamos que somente o uso de material biodegradável e aparelhos eletrônicos com volume elevado se mostraram com relevância estatística. Indivíduos mais velhos tendem a ter maior noção sobre o desenvolvimento e seus efeitos sobre o meio ambiente, e assim tendem a realizar mais ações para evitar a degradação do meio onde vivem. A poluição sonora é um dos grandes problemas nos dias atuais conforme foi observado por De Lacerda et al. ${ }^{9}$, em Curitiba, onde a maioria dos indivíduos do estudo relatou incômodo pelo ruído gerado na sua rua. No entanto, vemos novamente que crianças, adolescentes e jovens não apresentam consciência sobre este problema e, no futuro, podem se tornar adultos desprovidos de práticas ou atitudes ecologicamente corretas.

Em relação aos hábitos pessoais e ambiente (domínio D), observamos que pontos como os hábitos de jogar lixo no 
ambiente e cuspir no chão, assim como escovar os dentes após as refeições, foram relevantes, tornando-se mais freqüentes à medida que a idade avança. Estes pontos estão fortemente associados à relação do indivíduo com o ambiente, visto que aqueles que vêem o ambiente como o conjunto de coisas ao seu redor têm maior noção sobre o meio e tendem a não realizar tais práticas.

Dessa forma, pode-se perceber que as soluções podem ser conduzidas em dois sentidos, incluindo mudanças individuais e coletivas. É preciso que os profissionais de saúde tenham conhecimento da viabilidade das áreas de intervenção e compreendam suas funções e papéis na promoção da saúde, já que a educação em saúde pode desencadear mudanças de comportamento individual capazes de propiciar mecanismos de saúde nas camadas mais amplas da população, com reflexos sobre o meio ambiente.

\section{CONCLUSÕES}

A condução do programa de educação ambiental deve, portanto, valorizar os aspectos locais da cultura e do ambiente, com produção de material didático apropriado, possibilitando a reciclagem de professores e estimulando o protagonismo juvenil no enfrentamento dos problemas locais. Atividades práticas, visitas, excursões e promoção de campanhas devem ser incentivadas e apoiadas como forma de envolvimento criativo e consciente de crianças e jovens no equacionamento dos problemas ambientais, para que eles tornem adultos conscientes.

Neste estudo, demonstrou-se que a educação sanitária parece estar associada à faixa etária. Os dados do presente estudo sugerem que a educação em saúde deve ser mais bem desenvolvida nas escolas, para que as pessoas aprendam medidas sanitárias e preventivas. E, ainda, que programas atuais de Educação em Saúde não deixem de lado aqueles com alto grau de escolaridade, pois esses também podem ser desinformados para as questões de saúde. Neste contexto, o profissional de saúde exerce papel primordial como agente de promoção de saúde capaz de interagir com a população, levando informações sobre doenças transmitidas pela água e pelo lixo, bem como sobre as suas formas de prevenção, controle e tratamento.

A partir dos resultados obtidos, ações de educação em saúde e ambiente precisam ser deflagradas, dentre elas a realização de oficinas com dinâmicas, vídeos, cartilhas entre outros instrumentos para que os profissionais de saúde, principalmente os agentes comunitários de saúde, possam compreender a importância de seu papel enquanto educadores ambientais e levar este conhecimento a população da cidade.
4. Berlinck CN, Caldas ALR, Monteiro AHRR, Saito CH. Contribuição da educação ambiental na explicitação e resolução de conflitos em torno dos recursos hídricos. Ambient Educ 2003, 8: 117-30.

5. Secretaria Geral de Planejamento (RJ). Estudo socioeconômico2004. Itaperuna (RJ); 2005.

6. Guimarães MA. Dimensão ambiental na educação. In: Formação e trabalho pedagógico. Campinas (SP): Papirus; 1995. Coleção Magistério.

7. Comis R, Vieira DP, Picavêa JP, Querol E, Querol MVM. Atividades de EA visando a melhoria da qualidade de vida da população do CEANE, em Uruguaiana, RS: prevenção das zoonoses e doenças transmitidas pela água não tratada. Educação Ambiental em Ação [periódico on-line] 2005 dez/fev; [citado 26 out 2006] 11 (3): [aprox. 2 telas]. Disponível em: http:// www.revistaea.org/artigo.php?idartigo $=275$ \&class $=02$.

8. Freire P. Educação e mudança. Rio de Janeiro (RJ): Paz e Terra; 1983. 9. De Lacerda ABM, Magni C, Morata TC, Marques JM, Zannin PHT. Ambiente urbano e percepção da poluição sonora. Ambient Soc 2005 jul/dez; 8 (2): 85-98.

\section{Colaboradores}

L.M. Villar participou na idealização, no desenvolvimento da pesquisa e na redação do artigo; A.J. de Almeida colaborou na análise estatística e na redação do artigo; J.L.V. de Almeida, M.C.A. de Lima, L.F. Boechat realizaram as entrevistas e participaram da construção do banco de dados; V.S. de Paula participou no desenvolvimento da pesquisa, colaborou na análise dos dados e na redação do artigo.

\section{Agradecimentos}

À Faculdade Redentor, pelo financiamento da pesquisa, e aos discentes e docentes do Curso de Ciências Biológicas da Faculdade Redentor, pelo apoio ao projeto.

\section{Referências}

1. Faggionato S. Percepção ambiental. [on-line] 2005; [citado 26 out 2006]. Disponível em: http://educar.sc.usp.br.

2. Rosa LG, Silva MMP. Percepção ambiental de educandos de uma escola do ensino fundamental. Anais do $6^{\circ}$ Simpósio Ítalo Brasileiro de Engenharia Sanitária e Ambiental; 2002; Vitória (ES), Brasil. Vitória; 2002.

3. Fernandes RS, Pelissari VB. Como os jovens percebem as questões ambientais . Rev Aprender [periódico on- line] 2003 jul/ago; 13: 10-15. 


\section{ANEXO 1}

Figura 1:

Modelo de questionário sobre percepção ambiental aplicado para os moradores do Município de Itaperuna.

$\mathrm{N}^{0}$ de ordem

Idade

Sexo

\section{A. Relação indivíduo/ambiente:}

1. 0 que significa ambiente?

2. Quais doenças podem ser transmitidas pela água?

B. Ações individuais em favor da área ambiental:

1. Você escova os dentes com a torneira aberta?

[ ] sim [ ] não [ ] outra/não se aplica

2. Você fecha a torneira enquanto se ensaboa durante o banho?

[ ] sim [ ] não [ ] outra/não se aplica

3. Como você lava carros e quintais?

4. Você desliga aparelhos eletrodomésticos ou a luz quando não está em um dos cômodos da sua casa?

[ ] sim [ ] não [ ] outra/não se aplica

5. Você separa lixo orgânico (comida) do inorgânico (vidro, jornais, plástico) na hora de jogá-lo fora?

[ ] sim [ ] não [ ] outra/não se aplica

6. Você separa papel, vidro, plástico e metais na hora de jogar fora o lixo?

[ ] sim [ ] não [ ] outra/não se aplica

7. Você faz alguma reciclagem do seu lixo?

[ ] sim [ ] não [ ] outra/não se aplica

\section{Preocupação com o impacto ambiental e consumo:}

1. Você utiliza gás natural veicular (GNV) ou outro tipo de combustível no seu carro?

[ ] gasolina [ ] álcool [ ] GNV [ ] diesel [ ] outro [ ] não se aplica

2. Você procura comprar material biodegradável, como alguns detergentes?

[ ] sim [ ] não [ ] outra/não se aplica

3. Você procura comprar produtos somente em aerossóis que tenham em seu rótulo a inscrição "Não possui CFC"?

[ ] sim [ ] não [ ] outra/não se aplica

4. Você escuta aparelhos eletrônicos com volume elevado?

[ ] sim [ ] não [ ] outra/não se aplica

D. Hábitos pessoais e ambiente:

1. Você joga lixo na rua ou em rios?

[ ] sim [ ] não [ ] outra/não se aplica

2. Você escova os dentes após cada refeição, inclusive após comer doces, todos os dias?

[ ] sim [ ] não [ ] outra/não se aplica

3. Você lava as mãos com sabão ao se levantar de manhã, antes de comer e após ter ido ao banheiro?

[ ] sim [ ] não [ ] outra/não se aplica

4. Você cospe no chão?

[ ] sim [ ] não [ ] outra/não se aplica

5. Você realiza limpeza constante do local onde mora?

[ ] sim [ ] não [ ] outra/não se aplica 